\title{
Bring Publics back into Networked Public Relations Research: A Dual-Projection Approach for Network Ecology*
}

\author{
Alvin $\mathrm{Zhou}^{\dagger}$ \\ Annenberg School for Communication, University of Pennsylvania
}

\begin{abstract}
This essay critiques the absence of publics in networked public relations research, and proposes the dual-projection approach as a solution to simplify and analyze the multi-mode public relations network ecology (Yang \& Taylor, 2015). Compared to most previous studies that employ organization-centric networks where ties stand for hyperlinks, collaborations, or coalitions, the new approach projects organization-public relationships and public-public relationships onto interorganizational ties. By doing so, it 1) brings publics back into networked public relations research; 2) presents organizations and publics - the two most important subjects of public relations research - equally in the same network, 3) drives literature further away from a dyadic view of relationship management, and 4) constitutes one of the first techniques that can analyze direct and timely consequences of organization-public relationships in the network ecology. To demonstrate the new approach, the network of publics overlap is introduced and applied to US-based LGBTQ advocacy groups. The essay also discusses the theoretical inquiries needed to further dual-projection networks, and invites scholars to create novel ways to incorporate publics into their network studies using dual projection.
\end{abstract}

Keywords: network ecology, dual projection, social networks, publics, public-public relationships

\footnotetext{
*Pre-print version of the article published in Public Relations Review doi: 10.1016/j.pubrev.2019.03.004. I thank Subhayan Mukerjee, Sandra González-Bailón, Tian Yang, editors, and anonymous reviewers for their helpful comments on the manuscript. Previously, the manuscript was presented at the 68th annual meeting of the International Communication Association in the Public Relations Division. Data and code to replicate the main analyses presented in this manuscript are available at https://github.com/alvinyxz/DualProjection-Network-Ecology

${ }^{\dagger}$ Corresponding Author, alvinyxz@upenn.edu
} 
The network perspective has influenced many social science fields, such as organizational science (Borgatti \& Foster, 2003), communication research (Monge \& Contractor, 2003), and sociology (Watts, 2004). Public relations scholars have been using social network analysis in their studies since the early 2000s, and the network paradigm has gradually matured in recent years. The new paradigm combines social network analysis with the "relationship worldview of public relations" (Toth, 2010, p. 719), and has delivered studies that examined relationships on a macro level.

Scholarship in this new paradigm is still limited, but a pattern has emerged, as most articles examined interorganizational networks based on their interactions, hyperlinks, partnerships, and co-occurrences (e.g., Saffer, 2016; Taylor \& Doerfel, 2003; Wu, 2016; Yang \& Taylor, 2014). These studies only focused on organizations, and ignored other social entities in the network ecology (Yang \& Taylor, 2015), which makes them indistinguishable from organizational communication studies.

One-mode interorganizational networks might suit well with other disciplines, but it constitutes a serious problem specifically for networked public relations research: conventional one-mode networks cannot accommodate organizations and publics - the two most important subjects of public relations research - in the same graph. Existing network studies opted to drop publics and pick organizations as nodes, which led to the astounding absence of publics in networked public relations research.

This study discusses the dual-projection approach as a solution. More specifically, the essay argues that, by projecting organization-public relationships and public-public relationships onto interorganizational ties, scholars can bring publics back into networked public relations research. The essay encourages scholars to think of public relations networks in a dual-projection way and create novel network types to enrich and diversify the rising paradigm.

The paper is structured into four sections. First, the essay reviewed the origin and development of the network paradigm in public relations research, and discussed the network ecology approach (Yang \& Taylor, 2015) as the state-of-the-art theoretical understanding of the public relations relationship networks. Second, existing public relations studies that employed social network analysis were reviewed, with the absence of publics highlighted. Then, referencing recent articles on audience-centric networks (Ksiazek, 2011; Majó-Vázquez, Cardenal, \& González-Bailón, 2017; Mukerjee, Majó-Vázquez, \& González-Bailón, 2018; Taneja, 2017; Webster \& Ksiazek, 2012), the essay argues that public relations scholars can use the same dual-projection approach to create new network types for their empirical research. In the end, networks of publics overlap were constructed in a similar way to Mukerjee et al. (2018) for demonstration purposes, and applied to examine the network of 105 US-based LGBTQ advocacy organizations.

\section{The Network Paradigm of Public Relations Research}

The field of public relations has witnessed a surge of empirical studies that employed network analysis in recent years. These studies develop theories and inform practice by analyzing social networks and semantic networks in public relations contexts. These studies have signaled the rise of the network paradigm in public relations research. The network 
paradigm has been recognized as one of the possible ways for scholars to reevaluate public relations' role in contemporary societies (Yang \& Taylor, 2015).

The emergence of the network paradigm is the result of two complementing streams of scholarly efforts in the past few decades: a series of theoretical inquiries into the meaning of "relationships" in public relations research, and the concurrent development of network analysis techniques.

\subsection{Relationships as the Focal Concept of Public Relations Research}

In a comprehensive review of existing public relations paradigms, Toth (2010) enumerated six major theoretical frameworks that defined the field of public relations: crisis communication, critical theory, feminist theory, rhetorical theory, strategic management, and tactical communication. Toth (2010) concludes that the focus of public relations scholarship, starting around the new millennium, has been shifting away from organizations' communication tactics to organizations' relationship construction and cultivation.

The shift is manifested by the growing number of empirical studies in the strategic management paradigm, in which scholars explored how organizations should "strategically manage" their relationships with publics (Ledingham, 2003). Crisis communication literature follows the trend, and studied relationship building before, during, and after crises (e.g., Sweetser \& Metzgar, 2007). Numerous references of the stakeholder theory (Freeman, 1984) in public relations literature, and studies on interorganizational relationships (Ferguson, 2018) and organization-public relationships (Ledingham \& Bruning, 1998) also evince the shift. The dialogic public relations theory emphasizes relationship building as well (Kent \& Taylor, 2002).

The burgeoning network paradigm, discussed in this paper, is heavily influenced by the strategic management paradigm and the new "relationship worldview of public relations" (Toth, 2010, p. 719). However, scholars see relationships differently in these two paradigms. Relationship management studies explore the nuanced layers and facets of the relationship dyad between an organization and a public. Integrating concepts from interpersonal communication and social psychology among many other disciplines, they probe the meaning of relationships in public relations and try to measure them through scales, which is evident in the organization-public relationships literature (Broom, Casey, \& Ritchey, 1997; Bruning \& Ledingham, 1999; Huang, 2001). Networked public relations research does not explore these micro-level relational details, but rather treats relationships as the fundamental building blocks - termed "ties" or "edges" - of a network where organizations and publics are interrelated. This network perspective overcomes the strategic management paradigm's dyadic limitations, and broadens researchers' purview to the macro level where the webs of relationships are made visible and the relationship between an organization and a public becomes one but many relationship dyads around organizations (Heath, 2013; Yang \& Taylor, 2015). To map these relationship dyads, networked public relations research uses network analysis in their empirical studies. 


\subsection{The Development of Network Analysis}

Network analysis originates from the interdisciplinary field of network science. The social science side of network science, commonly referred to as social networks, was developed by mathematical sociologists. Decades of sociological studies have constructed and refined a series of mathematical measures of networks (e.g., centrality, transitivity, density, and centralization) and their interpretations in empirical research. Several widely-used network models have also been built and tested, such as the small-world network (Watts \& Strogatz, 1998) and the scale-free network (Barabási \& Albert, 1999). In recent years, network science has been informing the development of two new fields: computational social science (Lazer et al., 2009) and science of science (Fortunato et al., 2018).

Compared to sociologists, communication scholars employed social network analysis much later. In one of the first books on communication network theories, Monge and Contractor (2003) summarized social network analysis as a technique that enables communication researchers to "represent relational data and explore the nature and properties of those relations" (p. 35). It reduces a complex system to an abstract structure that could be studied using mathematical, computational, and statistical tools (Newman, 2010). This structure, in its simplest form, consists of two components-nodes (also known as vertices) and ties (also known as edges). Ties, standing for relationships, connect nodes that stand for entities. In communication literature, the nodes are usually communicative human agents, while the ties are relational activity, such as communication, following, collaboration, and endorsement.

The expanding literature seeing public relations as a relationship management function and the growing application of social network analysis in communication literature, both taking place in the early new millennium, respectively provided theoretical and methodological foundations for the network paradigm. Taylor and Doerfel (2003, 2005) published the first series of articles that addressed public relations research questions using social network analysis. As they precisely concluded, "public relations theory has been moving toward relational communication models," and social network analysis is uniquely situated to study relational models (Taylor \& Doerfel, 2005, p. 128).

\subsection{Competing Approaches to Relationships}

As discussed above, the strategic management paradigm and the network paradigm significantly differ in their approaches to relationships. Strategic management literature mostly takes an organization-centric worldview and studies how an organization's decision making may affect its relationship with one of its publics (Grunig, 2006; Toth, 2010). The network paradigm, instead, takes a network ecology approach and positions organizations as ordinary members of a complex ecology with diverse relationships (Yang \& Taylor, 2015). Figure 1 visually demonstrates the two paradigms.

\subsubsection{Strategic Management Paradigm}

Strategic management of relationships studies one specific relationship dyad between an organization and one of its publics. For example, in Figure 1 panel A, an organizationpublic relationship study might explore how a public relations campaign could potentially 
Figure 1: Visual Presentations of Strategic Management of Relationships and Network Ecology
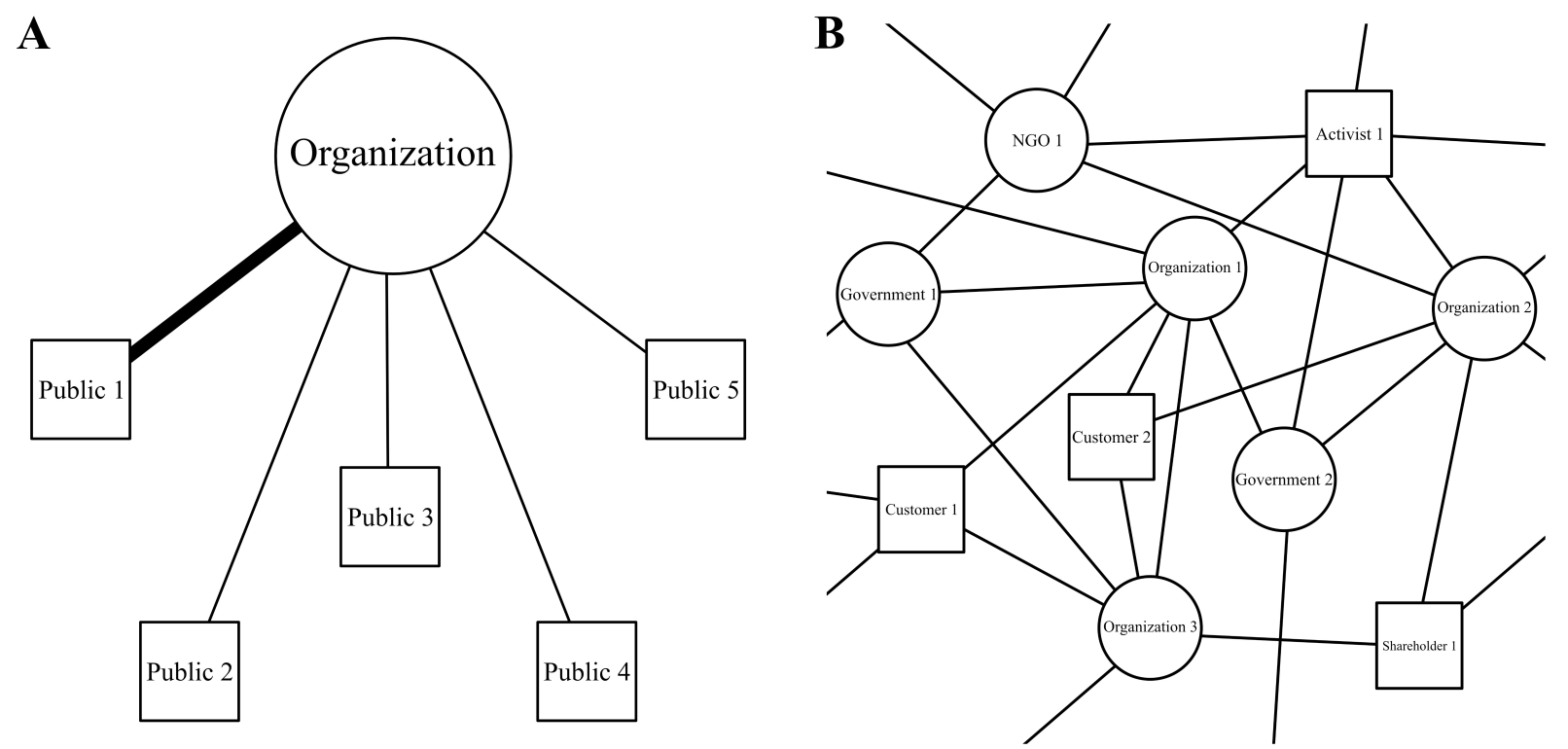

Note: Panel A visualizes the strategic management of relationships paradigm with the organization-public relationship between Organization and Public 1 highlighted. Panel B visualizes the network ecology approach from the network paradigm.

affect the relationship between Organization and its Public 1, usually dissected into four dimensions: trust, control mutuality, relational satisfaction, and relational commitment (Hon \& Grunig, 1999; Huang, 2001).

\subsubsection{Network Paradigm}

The network paradigm "views all organizations as networks embedded in other networks" (Yang \& Taylor, 2015, p. 100). Altogether, these networks constitute the network ecology, in which all organizations and publics equally reside. Therefore, the network ecology approach does not "relegate publics to a secondary role," and promises to "elevate publics to the status of communication equal with the organization," as Botan (1997, p. 196) argued about dialogues in public relations. According to Yang and Taylor (2015), this network ecology approach conceptualizes public relations as a management function that can affect two types of networks - the organizational-centric network and the network ecology network. As a result, the consequences of public relations interventions are beyond the four dimensions commonly measured by the organization-public relationship literature. Visualized in Figure 1 panel B, the network paradigm studies the consequences of public relations strategies and tactics on Organization 1's ego network - consisting of nodes such as Government 1, Customer 1, and Activist 1, and ties around Organization 1, and also on Organization 1's network ecology - the complete set of entities and relationships that constitutes the society 
in which Organization 1 operates.

However, techniques to analyze multi-mode networks have not been well developed, or not widely adopted (Borgatti \& Everett, 1997). The number of modes is the number of different kinds of nodes in a network. Therefore, the network ecology with multiple modes shown in Figure 1 panel B, theoretically constructed by Yang and Taylor (2015), is empirically difficult to analyze as a whole, using current network analysis techniques. Some scholars have utilized bipartite graphs to analyze two-mode networks (e.g., Doreian, 1979), but most network research in communication and public relations literature was conducted on one-mode networks.

Conventional one-mode networks might suit well with other communication disciplines and research questions, but it constitutes a serious problem specifically for networked public relations scholarship: one-mode networks can't accommodate organizations and publics - the two most important subjects of public relations research - in the same graph, because a one-mode network can only have one kind of nodes. Existing networked public relations studies opted to drop publics, pick organizations as nodes, and connect them through organizational activities, which led to the astounding absence of publics in networked public relations research. Public relations scholars have to think outside the box and utilize novel network types to better present the network ecology in which organizations actually reside. This study tries to bridge the gap by proposing an approach to bring publics back into networked public relations research. Before doing so, extant literature was reviewed and critiqued as follows.

\section{2 "Publics" in Networked Public Relations Research}

The concept of "publics" has been described as "one of the most conceptually troublesome notions in contemporary public relations" (Hallahan, 2000, p. 500). The origin of the concept can be traced back to Dewey (1927), a political philosopher who offered an issue-centered definition of publics - a group of people who face, recognize, and try to solve a certain social problem in a state. Dewey's definition focuses on politics, and is more often referred to as "issue publics" nowadays (e.g., Tremayne, Zheng, Lee, \& Jeong, 2006). Public relations scholars, instead, mostly studied organizational publics, but what organizational publics entail is still contested. Hallahan, Holtzhausen, van Ruler, Verčič, and Sriramesh (2007) reviewed the use of "publics" in public relations scholarship, and found that the word was used interchangeably with other related concepts, such as "audiences," "segments," "communities," "constituents," and most prominently "stakeholders."

"Often the terms stakeholder and public are used synonymously" (Grunig \& Repper, 1992 , p. 125) (emphasis in original text), and their difference was minor and subtle. In the series of work on the situational theory of publics, publics are conceptualized as active stakeholders - a segment of stakeholders who are aware of and active in their interactions with organizations (Grunig \& Repper, 1992; J.-N. Kim \& Grunig, 2011). Later work expanded the scope of publics, and argued that less aware and less active stakeholders could also constitute publics, such as latent publics, non-publics, and inactive publics, which further blurred the boundary between the two terms (Hallahan et al., 2007; Roser \& Thompson, 1995). "Stakeholder" (a term from management literature, e.g., Freeman, 1984) and "public" (a term from political theory, e.g., Dewey, 1927) seem to be converging in public relations 
literature, the subtle difference being "stakeholder" emphasizing the singularity of individuals and "public" highlighting the collectivity of groups.

Recent management communication literature has been expanding both concepts, as scholars started examining interorganizational networks in which organizations become stakeholders and publics of other organizations (e.g., Saffer, Yang, \& Taylor, 2018). This current essay sticks to the conventional definition of publics as a group of individual stakeholders "with which an organization wishes to establish and maintain a relationship" (Hallahan, 2000, p. 501), consistent with the organization-public relationship literature (Broom et al., 1997; Ledingham \& Bruning, 1998).

\subsection{The Absence of Publics in Networked Public Relations Research}

Despite the macro-level view brought by the network paradigm, most work in this field narrowly focused on semantic networks and interorganizational networks. In semantic networks, nodes are words or themes from public relations messages or media text, and ties are usually co-occurrences of two words or themes. In interorganizational networks, nodes are organizations, and ties are communicative activities among these organizations, such as hyperlink connections, actual telecommunication, and official partnerships. Organizational publics, one of the most prominent concepts in public relations research, have been absent from the literature. Table 1 enumerates all empirical networked public relations studies throughout the years, to the author's best knowledge.

Semantic networks are usually used to test the effect of public relations messages. By comparing network measures and central words of the semantic networks before and after the intervention, scholars can easily detect the change of the rhetoric, which otherwise could only be done by large-scale qualitative discourse analyses. Danowski (2008) presented one of the first studies using this method, in which they examined the long-term media effect of a university public relations campaign on local newspaper reporting with a quasi-experimental interrupted time-series design.

Interorganizational networks are used to uncover relationship networks among organizations. For example, Uysal and Yang (2013) examined WikiLeaks' mass self-communication network during its confrontation against Bank of America. They identified 434 websites that received or sent hyperlinks to WikiLeaks, mapped the hyperlink structure among these websites, and demonstrated WikiLeaks' power over other information sources with its dominant network position.

Studies on interorganizational networks have constituted the majority of networked public relations research in recent years. They focused on the interactions among organizations, and explored how public relations strategies and tactics affected organizations' relationships with other organizations. However, they inevitably, and also regrettably, downplayed the importance of organizational publics for these organizations. Yang and Taylor (2015) argued that networked public relations scholarship should examine diverse relationships around organizations, but the relationship between organizations and publics - one of the most extensively examined topics in previous public relations paradigms - is mostly absent in studies with semantic networks and interorganizational networks.

Himelboim, Golan, Moon, and Suto (2014) presented a study that involved organizational publics. They identified social mediators by examining the follower network of 
Table 1: Empirical Networked Public Relations Studies

\begin{tabular}{llll}
\hline Network Types & Source & Nodes & Ties \\
\hline Interorganizational & Current Study & Organizations & Publics \\
\hline Interorganizational & Saffer (2016) & Organizations & Interaction \\
& Saffer et al. (2018) & Organizations & Collaborations \\
& Sommerfeldt et al. (2011) & Organizations & Interaction \\
& Sommerfeldt (2013) & Organizations & Interaction \\
& Sommerfeldt et al. (2015) & Organizations & Interactions \\
& Taylor et al. (2003) & Organizations & Communication \\
& Taylor et al. (2005) & Organizations & Interactions \\
& Uysal et al. (2013) & Websites & Hyperlinks \\
& Wu (2016) & Organizations & Partnerships \\
& Wu et al. (2017) & Organizations & Co-occurrences \\
& Yang et al. (2014) & Organizations & Partnerships \\
& Yang et al. (2017) & Organizations & Co-occurrences \\
& Yang et al. (2018) & Organizations & Hyperlinks \\
& Yang et al. (2018) & Organizations & Hyperlinks \\
\hline Semantic & Danowski (2008) & Words & Co-occurrences \\
& Gilpin (2010) & Channels \& Words & Affiliations \\
& Kim et al. (2014) & Words & Co-occurrences \\
& Murphy (2010) & Words & Co-occurrences \\
& Podnar et al. (2012) & Themes & Cognitive links \\
& Schultz et al. (2012) & Themes & Co-occurrences \\
& Yang et al. (2012) & Words & Co-occurrences \\
& Yang et al. (2017) & Words & Co-occurrences \\
\hline Himelboim et al. (2014) & Twitter Users & Following \\
\hline Public & & &
\end{tabular}

US State Department's Twitter account, and found that informal mediators - most being US State Department's ordinary stakeholders - could help the organization reach its foreign publics, especially in the Middle East and North Africa. The authors also called for a broader understanding of organization-public relationships, beyond the dyadic examination of the relationship between one organization and one public. However, their work, by examining the following network of one organization and multiple publics, still falls short of extending the scope of networked public relations research to incorporate multiple organizations and multiple publics. As argued above and visually presented in Figure 1 panel $\mathrm{B}$, all organizations are embedded in networks with other organizations and publics. The ego network constructed by Himelboim et al. (2014) might have overlooked the effects of other organizations that did not have direct following relationships with the US State Department.

A visualization of the possible network types in a public relations network ecology is presented as Figure 2 panel $\mathrm{B}$ to conclude this discussion. As stated above, the existing networked public relations studies mostly examined direct interorganizational relationships among organizations - the tie between the two organizations in Figure 2 panel B, while downplayed organization-public relationships and public-public relationships in the network 
ecology.

\subsection{The Implications of Overlooking Publics in Networked Public Relations Research}

The absence of publics in networked public relations research has at least two negative implications.

First, the absence of publics per se limits the development of the network paradigm and signals a concerning departure from public relations scholarship's theoretical tradition. The importance of publics for public relations scholarship is incontestable. Scholars with functional and co-creational approaches have given different and competing definitions of public relations throughout the years, and most of them recognized the importance of both organizations and publics in their definitions (Botan \& Taylor, 2004; Coombs \& Holladay, 2007; Cutlip, Center, \& Broom, 2000; Edwards, 2012; Heath, 2013). The equal emphases on organizations and publics are also manifested by major public relations theories and previous paradigms, such as the excellence theory (Grunig, 1992), the situational theory of publics (Grunig, 1997; J.-N. Kim \& Grunig, 2011), the dialogic theory (Kent \& Taylor, 1998, 2002), and etc. Scholars with co-creational approaches hold even stronger opinions, as they defy the idea of public relations as an organizational function and celebrate the incorporation of other social entities into public relations research (Edwards, 2012; Heath, 2006; Holtzhausen, 2002; Toth \& Heath, 1992). Therefore, bringing publics back into networked public relations research is crucial for public relations scholarship's continuity, and also helps build the new paradigm's legitimacy.

Second, as Yang and Taylor (2015) argued, the network ecology approach brings new life to the scholarship of organization-public relationships, as it enables scholars to explore organization-public relationships and organization-public relationships' consequences on a macro level. But the interorganizational networks utilized by extant research cannot capture the direct consequences of public relations strategies on the dynamics of network ecology. For example, the consequences of an organization's terrible corporate public relations campaign or reputation crisis - which has seriously worsened its organization-public relationships and affected the network ecology - might not at all be captured by interorganizational networks based on hyperlinks or interactions. The organization might still collaborate with and provide hyperlinks to other organizations afterwards. In other words, without incorporating publics, networked public relations research cannot fully present the theoretical model of public relations network ecology (Yang \& Taylor, 2015), and cannot accurately measure organization-public relationships' consequences on the ecology.

As analysis techniques on multi-mode networks haven't been widely utilized and tested yet, how could public relations scholars bring publics back into networked public relations research? Here, I advocate using the dual-projection approach and discuss its implications for the network paradigm. A new network type is also proposed in which nodes stand for organizations and ties stand for publics-involved relationships. The next section presents the theoretical foundation of the new approach and the mathematical construction of the new method. 


\section{Dual Projection for Network Ecology}

\subsection{Audience-Centric Networks}

A series of communication research has been conducted by network scholars in recent years to develop and refine techniques and parameters for audience-centric network analyses of news consumption (Ksiazek, 2011; Mukerjee et al., 2018; Taneja, 2017; Taneja \& Webster, 2016; Webster, 2014; Webster \& Ksiazek, 2012). There has been a long history of advertising research and political communication research on audience duplication, but the network approach to analyzing relationships between information providers (i.e., news outlets) and information receivers (i.e., audiences) didn't mature until recent years (Goodhardt \& Ehrenberg, 1969; Ksiazek, 2011; Webster, 1985).

The network analysis of digital news consumption mainly focuses on its political implications, such as audience fragmentation and political polarization. In this stream of research, assumptions are that increased audience fragmentation - indicated by the fact that news outlets share fewer audiences, especially among those with different ideological slants - leads to higher political polarization. The high-choice media environment, the algorithm-driven news personalization technologies, and the evidence of exacerbated political polarization in US and UK have made these studies prominent in recent publications (see Anspach, 2017; Bakshy, Messing, \& Adamic, 2015; Boxell, Gentzkow, \& Shapiro, 2017; Del Vicario, Zollo, Caldarelli, Scala, \& Quattrociocchi, 2017; Flaxman, Goel, \& Rao, 2016; Fletcher \& Nielsen, 2017; Prior, 2007; Sunstein, 2017). For example, utilizing Nielsen's panel data, Webster and Ksiazek (2012) presented a long-tail distribution of US news outlets' audience reach and their audience-centric network. The low $0.86 \%$ centralization score in their network indicated a high level of equality in degree centralities and a large number of shared audiences among US news outlets. A group of scholars later improved Webster and Ksiazek (2012)'s approach, and examined audiences' digital news consumption in UK, US, and Spain (Majó-Vázquez et al., 2017; Mukerjee et al., 2018). The study on Spain examined citizens' news consumption behavior before and after a "link tax" law went into effect. Utilizing audience-centric networks, Majó-Vázquez et al. (2017) showed that the "link tax" law, which directly led to the shutdown of the news aggregator Google News Spain, increased the fragmentation of digital news consumption.

The network analysis of news outlets and audiences was challenged by the same twomode problem that we discussed above about networked public relations research. The news consumption behavior involves two types of agents - news outlets and audiences, and the ties connecting news agencies and audiences are affiliation ties, while the public relations network ecology mainly involves two types of agents as well-organizations and publics, and the ties connecting organizations and publics are affiliation ties.

The next section elaborates how political communication scholars resolved the problem using the dual-projection approach, and how public relations scholars can bring publics back into networked public relations research using the same technique.

\subsection{The Dual-Projection Approach for Two-Mode Networks}

To analyze two-mode networks, network scholars have recently devised the dual-

projection approach (Borgatti \& Everett, 1997; Borgatti \& Halgln, 2011; Everett \& Bor- 
gatti, 2013). Studies have shown that, compared to the direct approach (directly analyzing two-mode data), the dual-projection approach (projecting a two-mode network to a onemode network and then analyzing the projected network using standard techniques) loses little structural information and provides an easier way for community detection (Everett \& Borgatti, 2013; Melamed, 2014).

For a very long time, when analyzing media consumption, political communication scholars have dropped audiences and constructed one-mode media networks only using hyperlinks (e.g., Chang, Lau, \& Xiaoming, 2000; Himelboim, 2010). For example, Himelboim (2010) mapped the global hyperlink structure of news media by constructing a network with 73 countries being its nodes. Four major national news websites were selected to represent each country, and the tie weight between two nations was the number of cross-national hyperlinks that directed from one nation's websites to another nation's websites. They found the network to be highly hierarchical, with UK and US being the largest cross-national hyperlink sender and receiver.

Using hyperlinks to study digital media seems intuitive, as hyperlinks build the interweaving structure of the World Wide Web. However, compared to other organizationcentered fields that have also constructed networks using the "connecting websites by hyperlinks" strategy (e.g., business, Krebs, 2000; organizational communication, Shumate and Dewitt, 2008; science communication, Rogers and Marres, 2000), news consumption research is distinct because individuals' consumption behavior, which cannot be captured by hyperlinks, highly matters. In response, a group of communication scholars called for a departure from hyperlink analyses, and proposed an audience-centric approach to analyzing the World Wide Web using dual projection, illustrated in Figure 2 panel A (Ksiazek, 2011; Taneja, 2017).

In the audience-centric network, media outlets are linked by their shared audiences. In other words, the affiliation ties between media outlets and audiences are projected onto the ties among media outlets, and the network becomes a media-level projection of the bipartite network. Taneja (2017) constructed and compared the networks of 1000 globally popular websites - one based on hyperlinks and one based on audiences, and concluded that hyperlink networks - solely based on technical infrastructures - bore little resemblance to the actual World Wide Web.

This audience-centric approach based on dual projection brought audiences back into digital news consumption research (Mukerjee et al., 2018; Webster \& Ksiazek, 2012).

In the same vein, scholars can also bring publics back into networked public relations research using the same dual-projection approach. With dual projection, a public relations network could be an organization-level projection of a bipartite network, which links organizations through their relationships with publics, showcased in Figure 2 panel B. The constructed network is still an interorganizational network, since the nodes are organizations. However, the ties - previously standing for hyperlinks, interactions, partnerships, and etc - now stand for a set of publics-involved relationships. Put in a simple way, organizations are nodes and publics are ties in the dual-projection network.

For example, in Figure 2 panel B, the interorganizational tie between Organization 1 and Organization 2 measures the aggregated information of three ties - the organizationpublic relationship between Organization 1 and Public 1.2, the public-public relationship between Public 1.2 and Public 2.1, and the organization-public relationship between Orga- 
Figure 2: Dual Projection in a Public Relations Network Ecology

A
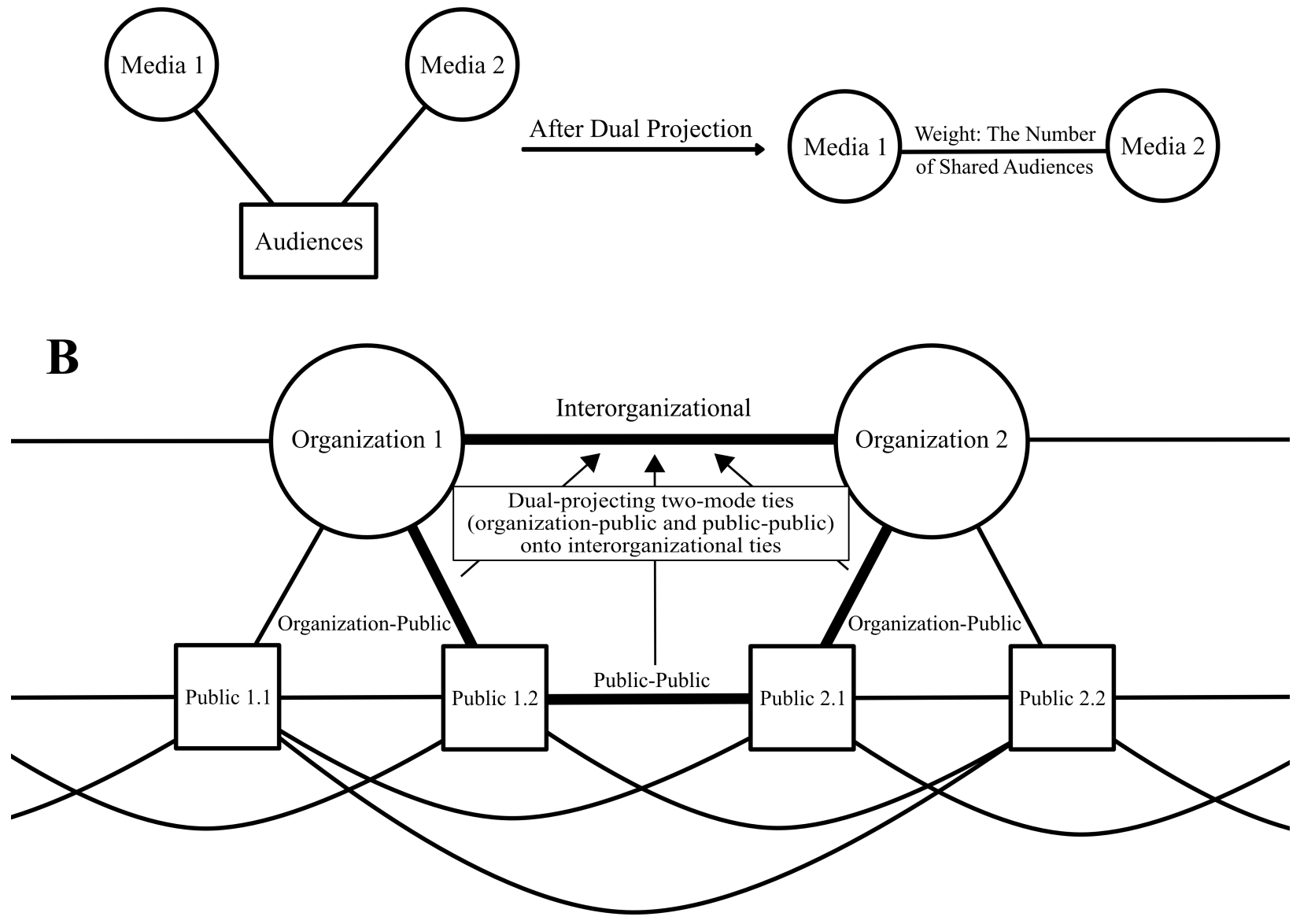

Note: 1. The two-mode model of the public relations network ecology highlights three relationship types that exist in a network ecology: interorganizational relationships, organization-public relationships, and public-public relationships, shown in Panel B. 2. Panel A shows the dual projection process in audience overlap networks. Panel B shows the dual projection process in a public relations network ecology. By projecting organization-public relationships and public-public relationships onto interorganizational ties, scholars can bring publics back into networked public relations research.

nization 2 and Public 2.1.

It should be noted that the panel B only highlighted one segment of the publics-based interorganizational tie between the two organizations, in the sense that Organization 1 and Organization 2 can also be connected through other sets of relationships. For example, if a corporate crisis seriously damaged the organization-public relationship between Organization 1 and Public 1.2, it would still be possible for Organization 1 to forge a tie with Organization 
2 through the "Organization 1 - Public 1.1 - Public 2.2 - Organization 2" path.

The complexity of the two-mode organization-public networks in Figure 2 panel B parallels the complexity of the multi-mode public relations network ecology, and also resembles the complexity of multistakeholder relationship management (Saffer et al., 2018).

By projecting publics-involved relationships onto interorganizational ties, this theoretical model provides public relations scholars with numerous possibilities to devise new network types for the network ecology (Yang \& Taylor, 2015). The essay follows Mukerjee et al. (2018) and presents one simple form - networks of publics overlap - to further demonstrate the theoretical foundations of the proposed model.

\subsection{Networks of Publics Overlap}

In traditional interorganizational networks that were constructed by previous literature, the tie between two organizations stood for their direct relationship based on hyperlinks, interactions, or partnerships. However, in reality, two organizations' relationship is much more complicated than that. Two organizations could have implicit relationships due to publics overlap without direct relationships. For example, two similar companies or nonprofit organizations might have few hyperlink connections due to competition, but since they cater for publics with similar interests, they might have much in common. The network of publics overlap is set to capture the implicit publics-involved relationships among organizations.

The following methodological construction is adapted from Mukerjee et al. (2018) who provided detailed explanations for each following step.

The network of publics overlap is a weighted network where nodes are organizations and ties are weighted as the absolute numbers of overlapped individuals in their shared publics. A crucial step in constructing the network is to filter out insignificant, random, and negative overlaps among organizations. ${ }^{1}$ Adapting Ronen et al.'s (2014) work on global language networks, Mukerjee et al. (2018) proposed a thresholding method for audiencecentered networks based on the $\phi$ and $t$ statistics. First, the strength of the publics overlapthe phi coefficient - is calculated as follows, which resembles the calculation of chi-square statistics.

$$
\phi_{i j}=\frac{D_{i j} N-A_{i} A_{j}}{\sqrt{A_{i} A_{j}\left(N-A_{i}\right)\left(N-A_{j}\right)}}
$$

In the equation, $D_{i j}$ stands for the number of individuals in the shared publics between $\mathrm{Org}_{i}$ and $\mathrm{Org}_{j} . \mathrm{N}$ is the population of the analyzed publics. $A_{i}$ and $A_{j}$ are respectively the numbers of individuals in each organization's publics. The $\phi$ coefficient is positive when the amount of overlapped individuals in two organizations' publics is higher than the expected value for a random overlap.

To eliminate insignificant ties, $t$ statistic is utilized.

$$
t_{i j}=\frac{\phi_{i j} \sqrt{N-2}}{\sqrt{1-\phi_{i j}^{2}}}
$$

\footnotetext{
${ }^{1}$ Negative overlaps refer to the negative values of the $\phi$ coefficients for some interorganizational ties.
} 
For a significant level of $p<.05$, the $t$ value needs to be $t_{i j}>1.96$, while for a significant level of $p<.01$, the $t$ value needs to be $t_{i j}>2.58$. With this $t$ statistic, it is easy to filter out insignificant, random, and negative overlaps, and keep significant overlaps among organizations. The following example eliminated insignificant ties that do not reach the significance level of $p<.01$. In other words, overlap ties with $t$ statistics not higher than 2.58 were eliminated.

Measures of the overlap network include weighted degree centrality (i.e., node strength), weighted eigenvector centrality, centralization (based on unweighted degree centrality), and etc (see Barrat, Barthelemy, Pastor-Satorras, \& Vespignani, 2004; Newman, 2004; Opsahl, Agneessens, \& Skvoretz, 2010, for discussions on centrality measures of weighted networks). Eigenvector centrality - the summed connections to other nodes, weighted by their centralities (Bonacich, 1987) - takes the centrality scores of adjacent nodes into account, and is better suited to measure the impact of organizations in an overlap network (Mukerjee et al., 2018). Moreover, since ties are weighted in networks of publics overlap, scholars can easily filter out weak ties and uncover the core of the network using other thresholding techniques (Borge-Holthoefer \& González-Bailón, 2017).

To further illustrate how to utilize the techniques and how to interpret the results, the network of publics overlap for major U.S. LGBTQ advocacy groups on Twitter was constructed.

\section{An Application: U.S. LGBTQ Advocacy Organizations on Twitter}

One hundred and fifty-nine major US-based LGBTQ advocacy organizations were identified. No official list exists, therefore, the information was manually collected by compiling publicly available information through Google and Wikipedia. Among them, 105 organizations have Twitter representation. Follower information of these 105 organizations was collected using Twitter API in Python. The data consist of 105 txt files that correspond to each organization and contain Twitter IDs of each organization's followers. Data were collected in March, 2018. Replication materials, including the dataset, R/Python scripts, and the list of examined organizations, are available online on the author's website.

$N$ - the population of analyzed publics - is the number of unique Twitter users in the dataset. In this example, $N=1,978,612 . D_{i j}$ is the number of shared followers between $\operatorname{Org}_{i}$ and $\mathrm{Org}_{j}$, while $\mathrm{A}_{i}$ and $\mathrm{A}_{j}$ are respectively the number of followers of $\mathrm{Org}_{i}$ and of $\mathrm{Org}_{j}$ on Twitter. The coefficient $\phi$ and $t$ - the strength and the significance of the overlap computed to filter out insignificant, random, and negative ties - are calculated using these parameters.

The significance of overlaps among US-based LGBTQ advocacy groups - indicated by the coefficient $t$-ranges from -350.6924 to 696.8426. Table 2 shows the pairs of organizations with the highest and lowest scores of overlap significance, and whether they are filtered out because of low $t$ statistics. After eliminating insignificant ties with $t$ statistics no larger than $2.58(\mathrm{~N}=380)$, the original network (with 105 nodes and a maximum of ${ }^{105} C_{2}$ ties) is left with 5080 ties. The network is then constructed and analyzed in $\mathrm{R}$ using the igraph package, with nodes being advocacy organizations and tie weights being the absolute numbers of individuals in shared publics among these organizations $\left(D_{i j}\right)$.

Table 3 shows ties with the largest weights in the publics overlap network for these

organizations. Unsurprisingly, influential and national LGBTQ advocacy groups-Human 
Table 2: Statistical Significance of Interorganizational Ties in the Network of Publics Overlap

\begin{tabular}{llccc}
\hline Organization 1 & Organization 2 & $\phi$ & $t$ & Filtered \\
\hline NCTE & Transgender Law Center & 0.4439 & 696.8426 & $\mathrm{~N}$ \\
GLSEN & PFLAG & 0.4375 & 684.4345 & $\mathrm{~N}$ \\
Sylvia Rivera Law Project & Audre Lorde Project & 0.3892 & 594.3094 & $\mathrm{~N}$ \\
PFLAG & GetEQUAL & 0.3826 & 582.4187 & $\mathrm{~N}$ \\
The Task Force & GetEQUAL & 0.3818 & 581.1536 & $\mathrm{~N}$ \\
\hline$\ldots$ & $\ldots$ & $\ldots$ & $\ldots$ & $\ldots$ \\
\hline Lesbian Avengers & NGLCC & 0.0018 & 2.5986 & $\mathrm{~N}$ \\
Equality Maryland & Lambda Legal & 0.0018 & 2.5973 & $\mathrm{~N}$ \\
Californians Against Hate & GLAAD & 0.0018 & 2.5771 & $\mathrm{Y}$ \\
\hline$\ldots$ & $\ldots$ & $\ldots$ & $\ldots$ & $\ldots$ \\
\hline Keshet & NOH8 Campaign & -0.0378 & -53.2594 & $\mathrm{Y}$ \\
NCTE & NOH8 Campaign & -0.0402 & -56.5673 & $\mathrm{Y}$ \\
Los Angeles LGBT Center & NOH8 Campaign & -0.0517 & -72.8615 & $\mathrm{Y}$ \\
Audre Lorde Project & NOH8 Campaign & -0.0665 & -93.6920 & $\mathrm{Y}$ \\
Human Rights Campaign & NOH8 Campaign & -0.2419 & -350.6734 & $\mathrm{Y}$ \\
\hline
\end{tabular}

Table 3: Ties with Largest Weights in the Constructed Network of Publics Overlap

\begin{tabular}{llr}
\hline Organization 1 & Organization 2 & Weight \\
\hline GLAAD & HRC & 209612 \\
Lambda Legal & HRC & 80467 \\
GLAAD & Lambda Legal & 66106 \\
Freedom to Marry & HRC & 57473 \\
GLSEN & HRC & 55340 \\
GLAAD & GLSEN & 53463 \\
NOH8 Campaign & Freedom to Marry & 50570 \\
PFLAG & HRC & 50110 \\
NOH8 Campaign & GLSEN & 49971 \\
$\ldots$ & $\ldots$ & $\ldots$ \\
\hline
\end{tabular}

Rights Campaign (HRC), GLAAD, and Lambda Legal - capture and share the highest number of publics, compared to other regional organizations. Table 4 shows organizations with the highest centrality scores, based on weighted degree centrality (node strength) and eigenvector centrality. The centralization of the network is $6.96 \%$ (based on degree centrality) and $5.52 \%$ (based on eigenvector centrality), which indicates a relatively high level of centrality inequality among these advocacy organizations, compared to the "media-audience" dualprojection networks constructed by previous work (see Majó-Vázquez et al., 2017; Mukerjee et al., 2018; Webster \& Ksiazek, 2012). In other words, publics resources are heavily and unequally occupied by several high-profile organizations, namely HRC, GLAAD, and Lambda Legal, with few publics resources distributed to other advocacy groups. Figure 3 visually presents the core of the network (with weight threshold set to 30,000), in which node size 
and tie thickness correspond to eigenvector centrality and tie weight.

Table 4: Top Centrality Scores in the Constructed Network of Publics Overlap (Rank in Parentheses)

\begin{tabular}{lrr}
\hline Organization & Weighted Degree Centrality & Eigenvector Centrality \\
\hline Human Rights Campaign (HRC) & $929916(1)$ & $1.0000(1)$ \\
GLAAD & $891173(2)$ & $0.9619(2)$ \\
Lambda Legal & $623800(3)$ & $0.6200(3)$ \\
GLSEN & $561237(4)$ & $0.5384(4)$ \\
Freedom to Marry & $540330(5)$ & $0.5177(5)$ \\
PFLAG & $537506(6)$ & $0.5107(6)$ \\
The Task Force & $531542(7)$ & $0.4790(7)$ \\
GetEQUAL & $424351(8)$ & $0.3765(9)$ \\
NCTE & $422977(9)$ & $0.3860(8)$ \\
GLAD & $405116(10)$ & $0.3574(10)$ \\
NOH8 Campaign & $403990(11)$ & $0.3186(11)$ \\
NCLR & $352358(12)$ & $0.3020(12)$ \\
American Foundation for Equal Rights & $307151(13)$ & $0.2771(14)$ \\
Los Angeles LGBT Center & $297832(14)$ & $0.2869(13)$ \\
Equality California & $280637(15)$ & $0.2291(15)$ \\
\hline
\end{tabular}

It's nearly impossible for scholars to construct a hyperlink-based or partnership-based coalition network for these advocacy organizations, because many of them do not even have well-functioned websites or participate in the same events. But examined from a public relations perspective, they inherently have relationships with each other. And public relations, either as an organizational management function or as a social co-creational approach, can affect these relationships. The network of publics overlap constructed here uncovers these inherent and intertwined relationships and makes it possible for scholars to study their dynamics.

By constructing the network of publics overlap, public relations scholars can ask new research questions such as:

- How a national/local anti-LGBTQ event/crisis redistributes publics resources among these advocacy organizations;

- How a public relations campaign affects the network ecology, quantitatively measured by centrality and centralization;

- How the core of the network will change when specific publics groups are selected as the population.

The dual-projection network, constructed by projecting organization-public relationships and public-public relationships onto interorganizational ties, also makes it possible for network scholars to analyze time-sensitive and publics-sensitive consequences of organizationpublic relationships (Yang \& Taylor, 2015). For example, a partnership between a local LGBTQ advocacy group and a national company, executed as a corporate social responsibility strategy by the company, might bring a large number of geologically diverse publics 
Figure 3: The Core of the Network of Publics Overlap for 105 US-based LGBTQ Advocacy Groups

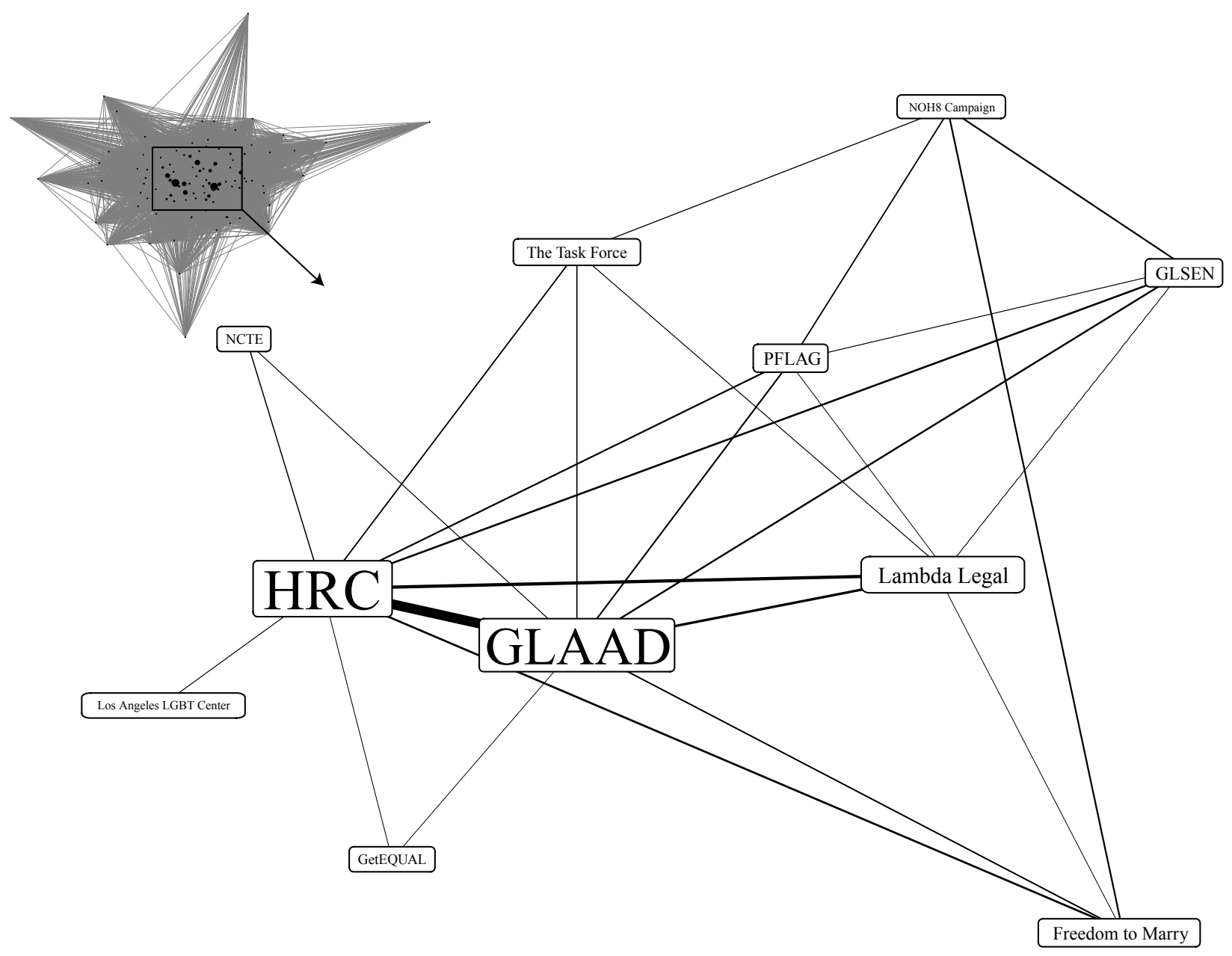

Note: The core network is constructed by eliminating ties with weights less than 30,000 from the original network and then deleting isolated nodes. In the visualized network, the tie width corresponds to the tie weight, and the node size corresponds to the eigenvector centrality of the organization. HRC (Human Rights Campaign) and GLAAD are the two most central nodes. In networks of publics overlap, public-public relationships are simplified as membership duplication.

to the local group, boost its influence within the queer community, and help establish its political power in national politics. These consequences will be reflected in the network of publics overlap, as the organization moves closer to the core of the network, gets increased centrality scores, and at the same time tones down the centralization of the whole network. The interorganizational network based on hyperlinks, interactions, or co-occurrences, instead, might see minimal changes during the whole time.

Admittedly, the dual-projection network is no way near the theoretical multi-mode 
network ecology model proposed by Yang and Taylor (2015). But compared to the network types utilized by previous work, networks of publics overlap have succeeded in incorporating two most important entities in the network ecology-organizations and publics - into one graph. More broadly, the dual-projection approach utilized by networks of publics overlap and discussed in this essay opens doors for public relations scholars to construct new network types that are beyond hyperlinks and are better suited for analyzing the network ecology.

\section{Discussion and Limitations}

This study critiques the absence of publics in networked public relations research, and argues that interorganizational networks based on hyperlinks, interactions, and cooccurrences - heavily utilized by existing studies - didn't accurately represent the landscape of the public relations network ecology, cannot directly capture the nuanced consequences of organization-public relationships, and overall limited the scope of networked public relations research. The network ecology at least has three types of relationship dynamics: interorganizational relationships, organization-public relationships, and public-public relationships. Only focusing on interorganizational activities hinders network scholars from developing a thorough understanding of the network ecology. It might also limit them from developing a network perspective of existing paradigms that involve publics, such as multistakeholder relationship management, organization-public relationships, and multistakeholder issue management. Further, the absence of publics signals a concerning departure from the theoretical tradition of the public relations scholarship which has asserted the equal importance of organizations and publics in its academic research.

To address this problem, this study calls for more scholarly attention to the dualprojection approach in network science. Constructing public relations networks in a dualprojection way can bring publics back into networked public relations research, and help simplify and analyze the complex multi-mode network ecology using existing network analytics. There are numerous ways to project organization-public relationships and public-public relationships onto interorganizational ties to construct a publics-involved network, as long as it helps answer public relations research questions. This study adapts the audience overlap networks suggested by Mukerjee et al. (2018) and proposes networks of publics overlap to demonstrate the dual-projection approach.

The dual-projection network argued in this essay incorporates publics into interorganizational ties, and represents the network ecology better than prior work that ignored entities other than organizations. It is more sensitive to public relations strategies and messages, and it is distinct from network research in other communication disciplines (e.g., organizational communication). The new network can be analyzed as a dependent variable and also as an independent variable. Scholars can ask how public relations strategies will affect the publics-based network as the intervention affects publics-based ties (comprised of organization-public relationships and public-public relationships). Scholars can also ask how organizations may devise different public relations strategies in response to their different positions in a publics-based network.

It should be noted that the purpose of the study is not to introduce networks of publics overlap as a method, but to discuss the implications of dual projection for networked public relations research. Dual projection is a way of network thinking, and it goes way beyond the 
network of publics overlap demonstrated above. By thinking of public relations networks in a dual-projection way, scholars can construct new network types and answer new research questions. Therefore, the essay is also inviting scholars to re-imagine what public relations networks could possibly be, and encouraging them to diversify the rising paradigm with novel studies. For example, studies on issue publics can use a dual-projection network thinking. Traditional work on issue publics usually focused on one single public or studied multiple publics separately (e.g., D. Kim, Kim, \& Nam, 2014; Krosnick, 1990; Tremayne et al., 2006). But in fact, issue publics do not exist independently from each other, and some of them might share mutual members and mutual interests. Using the dual projection approach (by projecting affiliation ties between issue publics and individuals/interests onto ties between issues), public relations scholars can explore the formation of issue publics and their network dynamics during a period of time. The point is, connecting organizations through their collaborations or hyperlinks - the strategy used by most existing network studies - is rather limited. The author hopes the current essay, by discussing the dual-projection approach, can start a meaningful discussion among public relations scholars on how to move the network paradigm forward with new perspectives.

Limitations of this study reside in the actual application of networks of publics overlaps in empirical public relations research and the theoretical meaning of public-public relationships, as discussed below.

\subsection{Ecology Beyond Twitter and Publics Beyond Followers}

The network of publics overlap needs mathematically accurate numbers of individuals in organizations' publics. To do so, using Twitter and organizations' follower data is one of the easiest ways to construct the overlap network for demonstration purposes. However, it also means that the Twitter universe was conceptualized as a network ecology and groups

of Twitter followers were conceptualized as publics, which is an oversimplification. Network ecology is far beyond Twitter, and publics are far beyond followers.

Network ecology as a public relations model was theoretically constructed in an actual society, in which "stakeholder groups are not always clearly identifiable" (Saffer et al., 2018, p. 123). Due to the diversity and complexity of identities and issues in contemporary societies, it remains a question of how public relations scholars can correctly identify organizations' publics in a network ecology. In this sense, the visual presentation of the network ecology is oversimplified. For example, Organization 1 and Shareholder 1 are not connected in Figure 1 panel B, which means Shareholder 1 is not a stakeholder of Organization 1 and Shareholder 1 is not in Organization 1's direct publics. But in reality, it's much more complicated than this dichotomous yes-or-no answer. The rise of the network society implies that every individual and every organization might be connected in some way and have a relationship between them (Castells, 2000; Yang \& Taylor, 2015).

Constructing networks of publics overlap needs a dichotomous answer to the question of whether an individual belongs to the publics of an organization, which is why Twitter and the follower data were used in this study. To extend the use of networks of publics overlap beyond Twitter and beyond dichotomous relationships, we need to further our understanding of stakeholder relationships in a network ecology. 


\subsection{Public-Public Relationships}

One of the most significant differences between the audience overlap networks (Mukerjee et al., 2018) and the networks of publics overlap discussed here is that, Mukerjee et al.'s (2018) model only considers the affiliation ties between Media and Audiences, while networks of publics overlap recognize the importance of public-public relationships - the relationships within and between publics.

In Figure 2 panel B, the interorganizational tie between Organization 1 and Organization 2 is a projection of the three publics-involved ties below it (two organization-public ties and one public-public tie). The examined public-public relationship between Public 1.2 and Public 2.1 in networks of publics overlap is membership duplication and overlap. Overlap is one of the simplest ways to characterize the relationships between two organizations' publics, but more organic facets of the public-public relationships can be measured. However, how to extend public-public relationships in dual-projection networks beyond overlap remains a challenge. One of the reasons is that the meaning of public-public relationships in public relations literature is rarely discussed.

Scholars have paid much attention to organization-public relationships in the past few decades. They have also started examining direct interorganizational relationships in recent years (e.g., existing networked public relations research). But the exploration of public-public relationships has not quite started.

Network ecology, in which all societal entities are possibly connected, reveals and highlights the importance of public-public relationships in public relations scholarship. Scholars have to recognize that different publics can have influences on each other, and their interactions might affect interorganizational relationships, organization-public relationships, and the ecology as a whole. For example in Figure 2 panel B, say Public 1.2 and Public 2.1 are two regional communities that have strong ties with Organization 1 and Organization 2 respectively. Public 1.2 strongly identifies with Organization 1, and Public 2.1 strongly identifies with Organization 2. A conflict between the two communities that worsens public-public relationships might also affect their organization-public relationships with the respective organizations, and change the direct interorganizational relationship between the two regional organizations. Sometimes it could happen without any organizational involvement. Public relations scholars should start exploring these nuanced facets and consequences of publicpublic relationships. Before doing so, it would be rather difficult to extend our understanding of public-public relationships beyond overlap.

Political communication and social psychology literature might be helpful for developing measures for public-public relationships. Political communication scholars have long studied how political publics (e.g., Democrats and Republicans) see each other, and how their evaluation of each other (public-public relationships) affects their relationships with the political party (organization-public relationships) and the relationship between the two parties (interorganizational relationships).

In conclusion, the absence of publics in networked public relations research can be resolved by constructing a network with organization-public relationships and public-public relationships projected onto interorganizational ties. To advance this approach, scholars have to recognize the importance of public-public relationships in a network ecology, and start meaningful discussions on its theories and measures. 


\section{References}

Anspach, N. M. (2017). The new personal influence: How our Facebook friends influence the news we read. Political Communication, 34(4), 590-606.

Bakshy, E., Messing, S., \& Adamic, L. A. (2015). Exposure to ideologically diverse news and opinion on Facebook. Science, 348(6239), 1130-1132.

Barabási, A.-L., \& Albert, R. (1999). Emergence of scaling in random networks. Science, $286(5439), 509-512$.

Barrat, A., Barthelemy, M., Pastor-Satorras, R., \& Vespignani, A. (2004). The architecture of complex weighted networks. Proceedings of the National Academy of Sciences, 101 (11), 3747-3752.

Bonacich, P. (1987). Power and centrality: A family of measures. American Journal of Sociology, 92(5), 1170-1182.

Borgatti, S. P., \& Everett, M. G. (1997). Network analysis of 2-mode data. Social Networks, $19(3), 243-269$.

Borgatti, S. P., \& Foster, P. C. (2003). The network paradigm in organizational research: A review and typology. Journal of Management, 29(6), 991-1013.

Borgatti, S. P., \& Halgln, D. S. (2011). Analyzing affiliation networks. In The SAGE handbook of social network analysis (pp. 417-433). Thousand Oaks, CA: SAGE Publications.

Borge-Holthoefer, J., \& González-Bailón, S. (2017). Scale, time, and activity patterns: Advanced methods for the analysis of online networks. In The SAGE handbook of online research methods (pp. 259-276). Thousand Oaks, CA: SAGE Publications.

Botan, C. (1997). Ethics in strategic communication campaigns: The case for a new approach to public relations. The Journal of Business Communication, 34(2), 188-202.

Botan, C., \& Taylor, M. (2004). Public relations: State of the field. Journal of Communication, 54 (4), 645-661.

Boxell, L., Gentzkow, M., \& Shapiro, J. M. (2017). Greater Internet use is not associated with faster growth in political polarization among US demographic groups. Proceedings of the National Academy of Sciences, 10612-10617.

Broom, G. M., Casey, S., \& Ritchey, J. (1997). Toward a concept and theory of organizationpublic relationships. Journal of Public Relations Research, 9(2), 83-98.

Bruning, S. D., \& Ledingham, J. A. (1999). Relationships between organizations and publics: Development of a multi-dimensional organization-public relationship scale. Public Relations Review, 25(2), 157-170.

Castells, M. (2000). The rise of the network society (2nd ed.). Malden, MA: Wiley-Blackwell.

Chang, T.-K., Lau, T.-y., \& Xiaoming, H. (2000). From the United States with news and more: International flow, television coverage and the world system. International Communication Gazette, 62(6), 505-522.

Coombs, W. T., \& Holladay, S. J. (2007). It's not just PR: Public relations in society. Malden, MA: Blackwell.

Cutlip, S. M., Center, A. H., \& Broom, G. M. (2000). Effective public relations. Upper Saddle River, NJ: Prentice Hall.

Danowski, J. A. (2008). Short-term and long-term effects of a public relations campaign on semantic networks of newspaper content: Priming or framing? Public Relations 
Review, 34(3), 288-290.

Del Vicario, M., Zollo, F., Caldarelli, G., Scala, A., \& Quattrociocchi, W. (2017). Mapping social dynamics on Facebook: The Brexit debate. Social Networks, 50, 6-16.

Dewey, J. (1927). The public and its problems. Oxford, UK: Holt.

Doreian, P. (1979). On the evolution of group and network structure. Social Networks, 2(3), $235-252$.

Edwards, L. (2012). Defining the "object" of public relations research: A new starting point. Public Relations Inquiry, 1(1), 7-30.

Everett, M., \& Borgatti, S. (2013). The dual-projection approach for two-mode networks. Social Networks, 35(2), 204-210.

Ferguson, M. A. (2018). Building theory in public relations: Interorganizational relationships as a public relations paradigm. Journal of Public Relations Research, 30(4), 164-178.

Flaxman, S., Goel, S., \& Rao, J. M. (2016). Filter bubbles, echo chambers, and online news consumption. Public Opinion Quarterly, 80(S1), 298-320.

Fletcher, R., \& Nielsen, R. K. (2017). Are news audiences increasingly fragmented? A cross-national comparative analysis of cross-platform news audience fragmentation and duplication. Journal of Communication, 67(4), 476-498.

Fortunato, S., Bergstrom, C. T., Börner, K., Evans, J. A., Helbing, D., Milojević, S., ... Barabási, A.-L. (2018). Science of science. Science, 359(6379), eaao0185.

Freeman, R. E. (1984). Strategic management: A stakeholder approach. Boston, MA: Pitman.

Goodhardt, G. J., \& Ehrenberg, A. S. C. (1969). Duplication of television viewing between and within channels. Journal of Marketing Research, 6(2), 169-178.

Grunig, J. E. (Ed.). (1992). Excellence in public relations and communications management. Mahwah, NJ: Lawrence Erlbaum Associates, Inc.

Grunig, J. E. (1997). A situational theory of publics: Conceptual history, recent challenges, and new research. In D. Moss, T. MacManus, \& D. Verčič (Eds.), Public relations research: An international perspective (pp. 3-48). London, England: International Thomson Business Press.

Grunig, J. E. (2006). Furnishing the edifice: Ongoing research on public relations as a strategic management function. Journal of Public Relations Research, 18(2), 151176.

Grunig, J. E., \& Repper, F. C. (1992). Strategic Management, publics, and issues. In J. E. Grunig (Ed.), Excellence in public relations and communications management (pp. 117-158). Mahwah, NJ: Lawrence Erlbaum Associates, Inc.

Hallahan, K. (2000). Inactive publics: the forgotten publics in public relations. Public Relations Review, 26 (4), 499-515.

Hallahan, K., Holtzhausen, D., van Ruler, B., Verčič, D., \& Sriramesh, K. (2007). Defining Strategic Communication. International Journal of Strategic Communication, 1(1), $3-35$.

Heath, R. L. (2006). Onward into more fog: Thoughts on public relations' research directions. Journal of Public Relations Research, 18(2), 93-114.

Heath, R. L. (2013). The journey to understand and champion OPR takes many roads, some not yet well traveled. Public Relations Review, 39(5), 426-431.

Himelboim, I. (2010). The international network structure of news media: An analysis of 
hyperlinks usage in news web sites. Journal of Broadcasting $\&$ Electronic Media, 54(3), 373-390.

Himelboim, I., Golan, G. J., Moon, B. B., \& Suto, R. J. (2014). A social networks approach to public relations on Twitter: Social mediators and mediated public relations. Journal of Public Relations Research, 26(4), 359-379.

Holtzhausen, D. R. (2002). Towards a postmodern research agenda for public relations. Public Relations Review, 28(3), 251-264.

Hon, L. C., \& Grunig, J. E. (1999). Guidelines for measuring relationships in public relations. Gainesville, FL: Institute for Public Relations.

Huang, Y.-H. (2001). Values of public relations: Effects on organization-public relationships mediating conflict resolution. Journal of Public Relations Research, 13(4), 265-301.

Kent, M. L., \& Taylor, M. (1998). Building dialogic relationships through the world wide web. Public Relations Review, 24 (3), 321-334.

Kent, M. L., \& Taylor, M. (2002). Toward a dialogic theory of public relations. Public Relations Review, 28(1), 21-37.

Kim, D., Kim, J.-H., \& Nam, Y. (2014). How does industry use social networking sites? An analysis of corporate dialogic uses of Facebook, Twitter, YouTube, and LinkedIn by industry type. Quality $\&$ Quantity, 48(5), 2605-2614.

Kim, J.-N., \& Grunig, J. E. (2011). Problem solving and communicative action: A situational theory of problem solving. Journal of Communication, 61(1), 120-149.

Krebs, V. (2000). Working in the connected world book network. IHRIM (International Association for Human Resource Information Management) Journal, 4 (1), 87-90.

Krosnick, J. A. (1990). Government policy and citizen passion: A study of issue publics in contemporary America. Political Behavior, 12(1), 59-92.

Ksiazek, T. B. (2011). A network analytic approach to understanding cross-platform audience behavior. Journal of Media Economics, 24 (4), 237-251.

Lazer, D., Pentland, A., Adamic, L., Aral, S., Barabasi, A.-L., Brewer, D., ... Van Alstyne, M. (2009). Computational social science. Science, 323(5915), 721-723.

Ledingham, J. A. (2003). Explicating relationship management as a general theory of public relations. Journal of Public Relations Research, 15(2), 181-198.

Ledingham, J. A., \& Bruning, S. D. (1998). Relationship management in public relations: Dimensions of an organization-public relationship. Public Relations Review, 24(1), 55-65.

Majó-Vázquez, S., Cardenal, A. S., \& González-Bailón, S. (2017). Digital news consumption and copyright intervention: Evidence from Spain before and after the 2015 "link tax". Journal of Computer-Mediated Communication, 22(5), 284-301.

Melamed, D. (2014). Community structures in bipartite networks: A dual-projection approach. PLoS ONE, 9(5), e97823.

Monge, P., \& Contractor, N. S. (2003). Theories of communication networks. Oxford, UK: Oxford University Press.

Mukerjee, S., Majó-Vázquez, S., \& González-Bailón, S. (2018). Networks of audience overlap in the consumption of digital news. Journal of Communication, 68(1), 26-50.

Newman, M. E. J. (2004). Analysis of weighted networks. Physical Review E, 70(5), 056131.

Newman, M. E. J. (2010). Networks: An introduction. Oxford, UK: Oxford University 
Press.

Opsahl, T., Agneessens, F., \& Skvoretz, J. (2010). Node centrality in weighted networks: Generalizing degree and shortest paths. Social Networks, 32(3), 245-251.

Prior, M. (2007). Post-broadcast democracy. Cambridge, UK: Cambridge University Press. Rogers, R., \& Marres, N. (2000). Landscaping climate change: a mapping technique for understanding science and technology debates on the World Wide Web. Public Understanding of Science, 9(2), 141-163.

Ronen, S., Gonçalves, B., Hu, K. Z., Vespignani, A., Pinker, S., \& Hidalgo, C. A. (2014). Links that speak: The global language network and its association with global fame. Proceedings of the National Academy of Sciences, 111 (52), E5616-E5622.

Roser, C., \& Thompson, M. (1995). Fear appeals and the formation of active publics. Journal of Communication, 45(1), 103-121.

Saffer, A. J. (2016). A message-focused measurement of the communication dimension of social capital: Revealing shared meaning in a network of relationships. Journal of Public Relations Research, 28(3-4), 170-192.

Saffer, A. J., Yang, A., \& Taylor, M. (2018). Reconsidering power in multistakeholder relationship management. Management Communication Quarterly, 32(1), 121-139.

Shumate, M., \& Dewitt, L. (2008). The north/south divide in NGO hyperlink networks. Journal of Computer-Mediated Communication, 13(2), 405-428.

Sunstein, C. R. (2017). \#Republic: Divided democracy in the age of social media. Princeton, NJ: Princeton University Press.

Sweetser, K. D., \& Metzgar, E. (2007). Communicating during crisis: Use of blogs as a relationship management tool. Public Relations Review, 33(3), 340-342.

Taneja, H. (2017). Mapping an audience-centric World Wide Web: A departure from hyperlink analysis. New Media \& Society, 19(9), 1331-1348.

Taneja, H., \& Webster, J. G. (2016). How do global audiences take shape? The role of institutions and culture in patterns of web use. Journal of Communication, 66(1), $161-182$.

Taylor, M., \& Doerfel, M. L. (2003). Building interorganizational relationships that build nations. Human Communication Research, 29(2), 153-181.

Taylor, M., \& Doerfel, M. L. (2005). Another dimension to explicating relationships: Measuring inter-organizational linkages. Public Relations Review, 31(1), 121-129.

Toth, E. L. (2010). Reflection on the field. In R. L. Heath (Ed.), The SAGE handbook of public relations (2nd ed., pp. 711-722). Thousand Oaks, CA: SAGE.

Toth, E. L., \& Heath, R. L. (Eds.). (1992). Rhetorical and critical approaches to public relations. Hillsdale, NJ: Lawrence Erlbaum Associates, Inc.

Tremayne, M., Zheng, N., Lee, J. K., \& Jeong, J. (2006). Issue publics on the web: Applying network theory to the war blogosphere. Journal of Computer-Mediated Communication, 12(1), 290-310.

Uysal, N., \& Yang, A. (2013). The power of activist networks in the mass self-communication era: A triangulation study of the impact of WikiLeaks on the stock value of Bank of America. Public Relations Review, 39(5), 459-469.

Watts, D. J. (2004). The "new" science of networks. Annual Review of Sociology, 30(1), 243-270.

Watts, D. J., \& Strogatz, S. H. (1998). Collective dynamics of 'small-world' networks. 
Nature, $393(6684), 440-442$.

Webster, J. G. (1985). Program audience duplication: A study of television inheritance effects. Journal of Broadcasting \&3 Electronic Media, 29(2), 121-133.

Webster, J. G. (2014). The marketplace of attention: How audiences take shape in a digital age. Cambridge, MA: MIT Press.

Webster, J. G., \& Ksiazek, T. B. (2012). The dynamics of audience fragmentation: Public attention in an age of digital media. Journal of Communication, 62 (1), 39-56.

Wu, D. (2016). Assessing resource transactions in partnership networks: US 100,000 Strong network of public diplomacy. Public Relations Review, 42(1), 120-134.

Yang, A., \& Taylor, M. (2014). A global perspective on public relations professionalism: Mapping the structure of public relations associations' international networks. Journalism \&3 Mass Communication Quarterly, 91 (3), 508-529.

Yang, A., \& Taylor, M. (2015). Looking over, looking out, and moving forward: Positioning public relations in theorizing organizational network ecologies. Communication Theory, 25(1), 91-115. 